\title{
Comparison of the effectiveness of positive thinking training and acceptance and commitment therapy on quality of life and resilience of people living with HIV
}

\author{
Pegah Mirzapour ${ }^{1}$, Firoozeh Zangeneh Motlagh ${ }^{1}$, SeyedAhmad SeyedAlinaghi ${ }^{2}$, Esmaeil Mehraeen ${ }^{3}$ \\ ${ }^{1}$ Department of Psychology, Arak Branch, Islamic Azad University, Arak, Iran \\ ${ }^{2}$ Iranian Research Center for HIV/AIDS, Iranian Institute for Reduction of High-Risk Behaviors, Tehran University of Medical \\ Sciences, Tehran, Iran \\ ${ }^{3}$ Department of Health Information Technology, Khalkhal University of Medical Sciences, Khalkhal, Iran
}

\begin{abstract}
Introduction: The purpose of this research was to know the effectiveness of positive thinking training and acceptance and commitment therapy (ACT) on quality of life and resilience of people living with HIV (PLHIV).

Material and methods: This study employed a quasi-experimental method, with pre-test/post-test design. Statistical sample size was 45 PLHIV, who were selected using purposive sampling method. They were randomly assigned into positive thinking $(n=15)$, ACT $(n=15)$, and control $(n=15)$ groups. Quality of life questionnaire by Ware and Sherbourne (1991) and Conner-Davidson resilience scale (2003) were used for all three groups (pre-test). Participants of the experimental groups attended eight 90-minute sessions of group training. Post-test was implemented two weeks after training. Multivariate and univariate analyses of variance (MANCOVA) were used to analyze the data.

Results: The results showed that positive thinking group training was effective in promoting quality of life and resilience. The results also demonstrated that acceptance and commitment therapy was effective in promoting quality of life and resilience. According to the findings, there was no significant difference between the effectiveness of positive thinking group training and acceptance and commitment therapy on quality of life and resilience of PLHIV $(p>0.05)$.

Conclusions: According to the obtained results, both training approaches (positive thinking and ACT) promoted quality of life and resilience of PLHIV, and there was no significant difference between the effectiveness of the two intervention approaches. Therefore, both interventions had beneficial impacts on lives of PLHIV.
\end{abstract}

HIV AIDS Rev 2022; 21, 1: 50-57 DOI: https://doi.org/10.5114/hivar.2021.112404

Key words: positive thinking approach, acceptance and commitment therapy, quality of life, resilience, PLHIV.

Address for correspondence: Firoozeh Zangeneh Motlagh, Department of Psychology, Arak Branch, Islamic Azad University, Arak, Iran, phone: + 989188620768 ,

e-mail: F-zanganeh@iau-arak.ac.ir

\section{Article history:}

Received: 10.08.2021

Revised: 09.10.2021

Accepted: 24.10.2021

Published: 04.01.2022
International Journal

of HIV-Related Problems

HIV \& AIDS

R e v i e w 


\section{Introduction}

Acquired immunodeficiency syndrome (AIDS) is an instance of an infection caused by human immunodeficiency virus (HIV). Despite significant advancements in HIV treatment, its' transmission is still common, with 39,782 new HIV-positive diagnoses in the United States in 2016, and approximately 2 million worldwide. About 1 in 8 people living with HIV (PLHIV) in the United States are unaware of their disease status $[1,2]$. Patients with chronic diseases, including AIDS, experience constant uncertainty and doubt, affecting physical, social, spiritual, psychological, and economic dimensions of their daily activities [3]. From a psychological perspective, PLHIV face various limitations in social and cultural environment, and are usually stressful experiences. Serious social and psychological consequences of HIV are an important factor contributing to spreading of the virus [4]. Research has shown that HIV is often stressful and affects the patients' quality of life [5].

Quality of life has been known as a significant measurement tool in epidemiological studies and clinical trials in the past few years [6]. Poor adherence to antiviral care leads to undesirable treatment outcomes. Sharing injection equipment, particularly needles and syringes, and penetrative sex without condoms are the main behavioral factors in fluencing the rate of disease transmission $[7,8]$. In addition, evidence shows that issues related to mental and physical health, social support, and employment status are associated with quality of life $[9,10]$.

Resilience is one of the most critical factors to consider among PLHIV. These people face numerous difficulties, such as trauma, interpersonal challenges, and economic problems [11], all of which are associated with reduced resilience [12]. Resilience is the capacity and capital, by which individuals can maintain psychological, behavioral, or social compatibilities despite adverse conditions and difficulties encountered along the way [13]. According to Yu et al. [14], the resilience of HIV patients is negatively associated with anxiety, depression, and stress. Based on findings of various studies, HIVinfected people experience low levels of resilience $[15,16]$. Given the above-mentioned evidence, PLHIV seem to face many problems and challenges in their individual and social lives. Therefore, they need psychological interventions to deal with psychological and social consequences of their disease.

Positive psychology is one of the most important interventions in the field of psychology. The positive thinking approach focuses on abilities, such as living with happiness, pleasure, problem-solving, and optimism, instead of stressing over weaknesses. Positive psychology emphasizes the vital role of valuable resources, abilities, and mental experiences of individuals. Experiences, such as psychological well-being, commitment, and satisfaction, hope and optimism, flow, and happiness are some examples [17]. Research has shown that positive thinking affects resilience and psychological compatibility [18] as well as resilience and psychological well-being [19] significantly.
Acceptance and commitment therapy (ACT) is another psychological intervention that can be performed in groups. Among different psychological approaches, ACT has significant effects on various psychological factors due to insistence on psychological flexibility, attracting the attention of researchers [20]. Studies have shown that ACT is effective in reducing depression $[21,22]$, and enhances psychological well-being of PLHIV [23].

Although there is growing empirical evidence about the impact of different treatments on various mental disorders and problems, few studies have compared positive thinking and ACT approaches, particularly concerning PLHIV. According to the issues raised, extensive research should be conducted in this field. Therefore, the present study examined whether there are differences between the effects of positive thinking and ACT on quality of life and resilience of PLHIV to empower this population.

\section{Material and methods}

\section{Methodology}

This study employed a quasi-experimental method with pre-test/post-test design. Statistical population of the study included PLHIV who were referred to the Behavioral Counseling Center of Imam Khomeini Hospital in Tehran, and had a medical record. Sampling method was purposive, with statistical sample size of 45 PLHIV. Participants were randomly assigned into positive thinking $(n=15)$, ACT $(n=15)$, and control $(n=15)$ groups.

\section{Research tools}

\section{Quality of life questionnaire (SF-36)}

A 36-item quality of life questionnaire (SF-36) by Ware and Sherbourne [24] was used in the study, consisted of 8 sub-scales, each of which included 2-10 items. Eight subscales of this questionnaire were physical function $(\mathrm{PF})$, role physical (RP), role emotional (RE), energy/fatigue (EF), emotional well-being (EW), social function (SF), pain $(\mathrm{P})$, and general health $(\mathrm{GH})$. Two general sub-scales of physical health and mental health were obtained from the integration of sub-scales. A lower or higher score indicated a lower or higher quality of life, respectively. Questions related to each sub-scale was added and divided by the number of questions in order to get eight sub-scales. Therefore, the scores of each sub-scale were ranging between 0 and 100. According to Karimpour [23], estimated Cronbach's $\alpha$ coefficient for this questionnaire ranges between 0.70 and 0.85 .

\section{Resilience scale}

Conner and Davidson have developed the questionnaire [26], and contains 25 items, each of which is scored on a Likert scale between zero (completely incorrect) and four (always correct).Therefore, the maximum score of this questionnaire is $100(25 \times 4=100)$, and the score of each subject 
Table 1. Structure of positive thinking group training sessions

\begin{tabular}{l|l}
\hline Training sessions & Structure of sessions \\
\hline Session 1 & $\begin{array}{l}\text { Establishing a therapeutic relationship, introducing oneself, acquainting people with the subject } \\
\text { of research, review and investigate people's problems }\end{array}$ \\
\hline Session 2 & $\begin{array}{l}\text { Teaching emotion recognition skills, the role of proper control of positive and negative emotions, } \\
\text { and their contributions to persistent happiness in life }\end{array}$ \\
\hline Session 3 & $\begin{array}{l}\text { Identifying the potential abilities of members, examining their weaknesses and strengths, } \\
\text { and developing specific strengths on the path to happiness, pleasure, commitment, and meaning }\end{array}$ \\
\hline Session 4 & Review of previous sessions and teaching stress management skills \\
\hline Session 5 & $\begin{array}{l}\text { Teaching appreciation; appreciation as a powerful tool to change anger and irritation into neutral } \\
\text { or even positive emotions; getting rid of resentment and hatred }\end{array}$ \\
\hline Session 6 & $\begin{array}{l}\text { Teaching participants to find purpose in life and encouraging them to think about long-term } \\
\text { and short-term goal setting }\end{array}$ \\
\hline Session 7 & Training and familiarity with negative and destructive beliefs to maintain happiness and enthusiasm \\
\hline Session 8 & $\begin{array}{l}\text { Review of previous sessions; awareness of the blessing of time, time management training, healthy } \\
\text { eating, and exercise in the daily schedule }\end{array}$ \\
\hline
\end{tabular}

Table 2. Structure of acceptance and commitment therapy group sessions

\begin{tabular}{l|l}
\hline Training sessions & Structure of sessions \\
\hline Session 1 & $\begin{array}{l}\text { Introduction, specification of group rules, creative helplessness: metaphors of the pit and two } \\
\text { mountains }\end{array}$ \\
\hline Session 2 & Metaphors of the polygraph, jelly doughnut, and tug-of-war with monster metaphors \\
\hline Session 3 & Assess problems, metaphors of two scales, two scale-pans, and box full of problems \\
\hline Session 4 & Metaphors of passengers on the bus, leaves floating on a stream, and teaching deep breaths \\
\hline Session 5 & A metaphor of chessboard and meditation exercises \\
\hline Session 6 & Value as behavior, selection, and identification of values; a metaphor of funeral/tombstone \\
\hline Session 7 & $\begin{array}{l}\text { Examining selection versus judgments/ decisions; examining the existing barriers to goals } \\
\text { and willingness to accept them }\end{array}$ \\
\hline Session 8 & $\begin{array}{l}\text { Teaching participants to be therapists themselves; all-or-nothing thinking: jumping exercise; } \\
\text { a metaphor of idle/lazy person }\end{array}$ \\
\hline
\end{tabular}

equals the sum of scores or total values obtained from each question. Kurdmirza [27] reported the reliability of 0.89 by Cronbach's $\alpha$, and validity of 0.88 by factor analysis method for resilience scale.

\section{Training procedure}

HIV infection, complete satisfaction for cooperation, absence of acute psychological and psychiatric disorders, no drugs abuse, no use of psychiatric medications, and literacy were the inclusion criteria. Furthermore, withdrawal from cooperation and absence from more than two training sessions were the exclusion criteria. The first intervention group received eight 90 -minute sessions of positive thinking group training. Table 1 summarizes the structure of these sessions.

ACT training was performed for the second intervention group in eight 90 -minute group sessions once a week. Table 2 shows a summary of ACT sessions.
Post-test was performed for all three groups after twoweeks training. Then, descriptive statistics, MANCOVA, and ANCOVA were applied to analyze the collected data.

\section{Results}

According to descriptive statistics and difference between the pre-test and post-test of the components of quality of life and resilience, the scores of experimental group improved in the post-test, while this difference was negligible in the control group. The value of Wilks' lambda in these variables was 0.002 . Since the significance level of this indicator was $p<0.01$, there was a significant difference between the experimental and control groups in terms of combination of dependent variables (quality of life and resilience) in the research sample. Given the significance of this indicator and the effect of independent variable on linear combination of the dependent variable, the second section examined 
Table 3. Inferential statistics indices used to calculate multivariate analysis of covariance

\begin{tabular}{|c|c|c|c|c|c|c|}
\hline Source of change/Variables & Sum of squares & df & Mean of squares & F-test & $p$-value & $\mathrm{Eta}^{2}$ \\
\hline \multicolumn{7}{|l|}{ Effect of experimental variable } \\
\hline Physical function & $9,208.29$ & 2 & $4,604.14$ & 58.52 & 0.001 & 0.77 \\
\hline Physical health impairment & $8,092.08$ & 2 & $4,046.04$ & 52.52 & 0.001 & 0.76 \\
\hline Emotional health impairment & $12,932.98$ & 2 & $6,466.49$ & 70.48 & 0.001 & 0.81 \\
\hline Energy/ fatigue & $10,214.97$ & 2 & $5,107.48$ & 102.98 & 0.001 & 0.86 \\
\hline Emotional well-being & $10,226.02$ & 2 & $5,113.01$ & 113.57 & 0.001 & 0.87 \\
\hline Social function & $8,021.14$ & 2 & $4,010.57$ & 81.01 & 0.001 & 0.83 \\
\hline Pain & $11,027.81$ & 2 & $5,513.90$ & 63.45 & 0.001 & 0.79 \\
\hline General health & $8,956.99$ & 2 & $4,478.50$ & 89.57 & 0.001 & 0.84 \\
\hline \multicolumn{7}{|l|}{ Error } \\
\hline Physical function & $2,675.00$ & 34 & 78.68 & - & - & - \\
\hline Physical health impairment & $2,619.39$ & 34 & 77.04 & - & - & - \\
\hline Emotional health impairment & $3,119.49$ & 34 & 91.75 & - & - & - \\
\hline Energy/ fatigue & $1,686.37$ & 34 & 49.60 & - & - & - \\
\hline Emotional well-being & $1,530.67$ & 34 & 45.02 & - & - & - \\
\hline Social function & $1,683.33$ & 34 & 49.51 & - & - & - \\
\hline Pain & $2,954.85$ & 34 & 86.91 & - & - & - \\
\hline General health & $1,700.06$ & 34 & 50.00 & - & - & - \\
\hline
\end{tabular}

whether each of the dependent variables was affected separately from the independent variable.

Hypothesis 1. There is a significant difference between positive thinking group training and acceptance and commitment therapy concerning the quality of life of PLHIV.

According to the results shown in Table 3, the calculated $F$ for the experimental variable in all components of quality of life was greater than the critical value of $\mathrm{F}$ (with $\mathrm{df}$ and $p<0.01$ ), leading to the null hypothesis rejection. It can be concluded with $99 \%$ confidence that there was a significant difference between the mean of all components of quality of life in the experimental (exposed to independent variable) and control groups in the study population. According to the calculated effect size, the independent variable can explain as a high percentage of the variance of all components of quality of life of the study sample.

The result of F-test indicated a significant difference between the mean of all components of quality of life in terms of the intervention approach. Paired comparisons were conducted using Bonferroni test.

Based on Table 4, the null hypothesis was rejected because the significance level of Bonferroni test was $>0.05$. It can be concluded that there was no significant difference between the means of quality of components in positive thinking group therapy and ACT.

Hypothesis 2. There is a significant difference between positive thinking group training and acceptance and commitment therapy concerning the resilience of PLHIV.

According to the results of Table 5, the calculated $\mathrm{F}$ for the experimental variable (55.71) was greater than the critical value of $\mathrm{F}$ (with $\mathrm{df}$ of 2.41 and $p<0.01$ ), leading to the null hypothesis rejection. It can be concluded with $99 \%$ confidence that there was a significant difference between the mean of resilience in the experimental (exposed to the independent variable) and the control groups in the study population. According to the calculated effect size, the independent variable can explain $73 \%$ of the variance of resilience in the study sample.

The result of F-test indicated a significant difference between the mean of resilience in terms of the intervention approach. Paired comparisons were conducted using Bonferroni test.

According to the results shown in Table 6, the null hypothesis was rejected because the significance level of Bonferroni test was $<0.01$. Therefore, it can be concluded that there was no significant difference between the mean of resilience in positive thinking group therapy and ACT.

\section{Discussion}

The present study aimed to compare the effectiveness of positive thinking group training and acceptance and commitment therapy on the quality of life and resilience of PLHIV.

According to the results of the study, the null hypothesis was rejected because the significance level of Bonferroni test was $>0.05$. Hence, it can be concluded that there was no significant difference between the effectiveness of the positive thinking group training approach and the acceptance and commitment therapy on the quality of life among PLHIV. 
Table 4. Pairwise mean comparison of quality of life in terms of intervention approach from Bonferroni test

\begin{tabular}{|c|c|c|c|c|c|c|}
\hline Variable/Group & Mean & \multicolumn{2}{|c|}{ Comparisons } & Mean difference & Standard error & $p$-value \\
\hline \multicolumn{7}{|l|}{ Physical function } \\
\hline Positive thinking & 65.27 & \multirow{2}{*}{ Positive thinking } & ACT & -1.94 & 3.37 & $>0.9$ \\
\hline ACT & 67.21 & & Control & 33.41 & 3.49 & 0.001 \\
\hline Control & 31.86 & ACT & Control & 35.35 & 3.70 & 0.001 \\
\hline \multicolumn{7}{|c|}{ Physical health impairment } \\
\hline Positive thinking & 68.10 & \multirow{2}{*}{ Positive thinking } & ACT & -1.59 & 3.34 & $>0.9$ \\
\hline $\mathrm{ACT}$ & 69.69 & & Control & 31.43 & 3.46 & 0.001 \\
\hline Control & 36.67 & ACT & Control & 33.02 & 3.66 & 0.001 \\
\hline \multicolumn{7}{|c|}{ Emotional health impairment } \\
\hline Positive thinking & 67.99 & \multirow{2}{*}{ Positive thinking } & ACT & -1.97 & 3.64 & $>0.9$ \\
\hline ACT & 69.96 & & Control & 39.75 & 3.77 & 0.001 \\
\hline Control & 28.24 & ACT & Control & 41.72 & 3.99 & 0.001 \\
\hline \multicolumn{7}{|l|}{ Energy/fatigue } \\
\hline Positive thinking & 67.61 & \multirow{2}{*}{ Positive thinking } & $\mathrm{ACT}$ & -1.35 & 2.68 & $>0.9$ \\
\hline ACT & 68.96 & & Control & 35.52 & 2.77 & 0.001 \\
\hline Control & 32.09 & ACT & Control & 36.86 & 2.94 & 0.001 \\
\hline \multicolumn{7}{|l|}{ Emotional well-being } \\
\hline Positive thinking & 67.90 & \multirow{2}{*}{ Positive thinking } & $\mathrm{ACT}$ & -2.66 & 2.55 & 0.91 \\
\hline ACT & 70.57 & & Control & 34.90 & 2.64 & 0.001 \\
\hline Control & 33.00 & ACT & Control & 37.56 & 2.80 & 0.001 \\
\hline \multicolumn{7}{|l|}{ Social function } \\
\hline Positive thinking & 62.74 & \multirow{2}{*}{ Positive thinking } & ACT & -1.90 & 2.67 & $>0.9$ \\
\hline ACT & 64.65 & & Control & 31.13 & 2.77 & 0.001 \\
\hline Control & 31.61 & ACT & Control & 33.04 & 2.93 & 0.001 \\
\hline \multicolumn{7}{|l|}{ Pain } \\
\hline Positive thinking & 67.70 & \multirow{2}{*}{ Positive thinking } & $\mathrm{ACT}$ & -3.23 & 3.54 & $>0.9$ \\
\hline ACT & 70.94 & & Control & 36.01 & 3.67 & 0.001 \\
\hline Control & 31.70 & ACT & Control & 39.24 & 3.89 & 0.001 \\
\hline \multicolumn{7}{|l|}{ General health } \\
\hline Positive thinking & 63.44 & \multirow{2}{*}{ Positive thinking } & ACT & -1.23 & 2.69 & $>0.9$ \\
\hline $\mathrm{ACT}$ & 64.67 & & Control & 33.27 & 2.79 & 0.001 \\
\hline Control & 30.16 & $\mathrm{ACT}$ & Control & 34.51 & 2.95 & 0.001 \\
\hline
\end{tabular}

Table 5. Inferential statistics indices used to calculate multivariate analysis of covariance

\begin{tabular}{|c|c|c|c|c|c|c|}
\hline Source of change & Sum of squares & df & Mean of squares & F-test & $p$-value & $\mathrm{Eta}^{2}$ \\
\hline \multicolumn{7}{|l|}{ Resilience } \\
\hline Pretest effect & 1674.62 & 1 & $1,674.62$ & 19.53 & 0.001 & 0.32 \\
\hline Experimental variable effect & 9551.61 & 2 & $4,775.81$ & 55.71 & 0.001 & 0.73 \\
\hline Error & 3514.98 & 41 & 85.73 & - & - & - \\
\hline
\end{tabular}

The results of the present study are in line with the results obtained by $[21,22,28-30]$.

In explaining the result of the present hypothesis, it can be argued that motivation, goal selection, emotion con- trol, perseverance, initiation, and persistence in the face of failure are all concepts considered in positive thinking training and contributing to individuals' quality of life. Accordingly, those who participated in the positive think- 
Table 6. Pairwise mean comparison of resilience in terms of intervention approach from Bonferroni test

\begin{tabular}{|c|c|c|c|c|c|c|}
\hline Variable/Group & Mean & \multicolumn{2}{|c|}{ Comparisons } & Mean difference & Standard error & $p$-value \\
\hline \multicolumn{7}{|l|}{ Resilience } \\
\hline Positive thinking & 76.43 & \multirow{2}{*}{ Positive thinking } & ACT & -3.71 & 3.40 & 0.84 \\
\hline $\mathrm{ACT}$ & 80.15 & & Control & 29.21 & 3.39 & 0.001 \\
\hline Control & 47.22 & $\mathrm{ACT}$ & Control & 32.92 & 3.43 & 0.001 \\
\hline
\end{tabular}

ing course could implement the correct methods of goal setting, self-awareness, time management, etc., during their lives by knowing and understanding the components of positive thinking. Therefore, the quality of life of participants in the positive thinking training improved. On the other hand, the participants were taught to accept the notion that suffering is a part of normal human experience during the course of ACT. They learned to react more adaptively and correct some of their verbal associations with pain by accepting it as merely another experience in life, which facilitates dealing with problems [21]. This approach not only does not talk about mental illness and its transformation into mental health but also assumes that the goal of a healthy life is not associated with good or bad feelings. Psychologically, undesirable thoughts and feelings represent mental health just as good thoughts and feelings do [31]. Therefore, both approaches affect the quality of life of PLHIV with different techniques but same principles, and there was no significant difference between the two intervention methods in terms of effectiveness. The trust in the emotional support by the family increases, and the lack of confidence decreases as PLHIV receive positive thinking training.

Arjun et al. [30] showed that social support increased scores of individuals' quality of life. Ghisvand et al. [6] also indicated encouraging and significant effects of that positive social support on the quality of life of PLHIV. Thus, positive thinking and ACT increase the resilience of HIV patients. Results obtained by Mohammadpour Doghabadi [29] are in line with the results of the present study, and show group therapy with intervention by hope method increasing quality of life in PLHIV.

According to the results of the study, the null hypothesis was rejected because the significance level of Bonferroni test was $>0.01$. Therefore, it can be concluded that there was no significant difference between the effectiveness of positive thinking group training approach and acceptance and commitment therapy on the resilience of PLHIV. In other words, both positive thinking group training and ACT affect the resilience of PLHIV, and there was no significant difference between their effectiveness.

The results of the present study are in line with the results obtained by previous research $[18,19,32,33]$. In explaining the results of the current work, it can be argued that when PLHIV receive ACT, they become aware of the cause of their behaviors and try to improve their thoughts and attitudes. Indeed, ACT leads to more flexible behavioral patterns and consequently, a higher degree of resilience. On the other hand, positive thinking training provides individuals with techniques to increase hope and optimism. Hope leads to improvement of negative thoughts and emotions in unfavorable life conditions of optimistic people, leading to progress of resilience in stressful life events. Positive people manage their negative emotions in unfavorable life situations [33]. Therefore, hope and positive thinking improve the resilience of individuals.

According to Heyes et al. [34], the main goal of ACT was to establish psychological flexibility, which means creating the ability to make appropriate practical selections among different options, not just performing or imposing an action to avoid disturbing thoughts, feelings, memories, or desires. Cognitive skills can improve resilience by increasing individuals' abilities to regulate emotions and coping skills. Consistent with the results of the present study, Mohammadinejad and Nikonejad [32] showed that ACT could increase psychological well-being and resilience. In line with the results of the current paper, Ghasemi Khaneghah [18] indicated significant effects of positive thinking psychotherapy on the level of resilience and psychosocial compatibility of cancer patients. As higher levels of resilience can improve quality of life, PLHIV who increase their resilience can cope better with life problems and show more flexibility. Therefore, both approaches affect the resilience of people with HIV through different but principal techniques, and there was no significant difference between these two interventions in terms of effectiveness.

The present study has some limitations. Since this study was conducted among PLHIV, caution should be taken in generalizing the findings to other groups of individuals. Other limitations of this research, which were beyond the control of the researcher, included the differences in personal, psychological, cultural, and social characteristics of the participants. Despite significant efforts, the effect of some factors, such as the passage of time and experience of the subjects, could not be overlooked to control the confounding variables. Hence, it is recommended to teach the basic principles of positive thinking approach and acceptance and commitment therapy to medical staff of specific diseases in medical centers. Doing research on wider samples, using random sampling method, and following therapeutic effects can help to generalize the results and confirm the stability of the findings over time.

According to the results, both training approaches, such as positive thinking and ACT approach, promoted 
the quality of life and resilience of PLHIV, and there was no significant difference between the effectiveness of the two intervention approaches. Therefore, both interventions had beneficial impacts on the lives of PLHIV.

\section{Acknowledgements}

The authors would like to thank the staff for their contributions. This article is extracted from the Ph.D. dissertation by Pegah Mirzapour. Dr. Firoozeh Zangeneh Motlagh, as the corresponding author, Dr. SeyedAhmad SeyedAlinaghi, as the supervisor, and Dr. Esmaeil Mehraeen, as the advisor, collaborated on this project. This study obtained its ethical approval from the Research committee of Islamic Azad University, Arak Branch Code: IR.IAU.ARAK. REC.1400.002.

\section{Conflict of interest}

The authors declare no conflict of interest.

\section{References}

1. Riddell J, Rivet Amico K, Mayer KH. HIV preexposure prophylaxis: a review. JAMA 2018; 319: 1261-1268.

2. Paydary K, Khaghani P, Emamzadeh-Fard S, Alinaghi SA, Baesi K. The emergence of drug resistant HIV variants and novel antiretroviral therapy. Asian Pac J Trop Biomed 2013; 3: 515-522.

3. Mishel MH. Theories of uncertainty in illness. In: Smith M, Liehr P (eds.). Middle range theory for nursing. $3^{\text {rd }}$ ed. New York: Springer; 2013, p. 53-86.

4. Alizadeh N, Farrokhi NA. Investigating the predictive pattern of psychological well-being based on the culture of perceived parenting styles in people living with HIV (HIV). International Conference on Psychopathological Culture and Education. Iranian Psychological Association, Al-Zahra University, 2017.

5. Andersson GZ, Reinius M, Eriksson LE, et al. Stigma reduction interventions in people living with HIV to improve healthrelated quality of life. Lancet HIV 2019, doi: 10.1016/s2352-3018 (19)30343-1.

6. Ghisvand H, Higgs P, Noroozi M, et al. Social and demographical determinants of quality of life in people who live with HIV/AIDS infection: evidence from a meta-analysis. Biodemography Soc Biol 2020; 65: 57-72.

7. Mwesiga EK, Mugenyi L, Nakasujja N, et al. Depression with pain co morbidity effect on quality of life among HIV positive patients in Uganda: a cross sectional study. Health Qual Life Outcomes 2015; 13: 206.

8. Khalili H, Rohani R, Seyedalinaghi S, Hajiabdolbaghi M, DashtiKhavidaki S, Talasaz AH. Adherence to Antiretroviral Therapy Among Iranian HIV/AIDS Patients. Curr Clin Pharmacol 2012; 7: 111-115.

9. Lan GL, Yuan ZK, Clements-Nolle KD, et al. Social capital and quality of life among people living with HIV/AIDS in Southeast China. Asia Pac J Public Health 2016; 28: 325-335.

10. Rüütel K, Pisarev H, Loit HM, Uusküla A. Factors influencing quality of life of people living with HIV in Estonia: A cross-sectional survey. J Int AIDS Soc 2009; 12: 13.

11. Dale S, Cohen M, Weber K, Cruise R, Kelso G, Brody L. Abuse and resilience in relation to HAART medication adherence and HIV viral load among women with HIV in the United States. AIDS Patient Care STDs 2014; 28: 136-143.
12. Langebeek N, Gisolf EH, Reiss P, et al. Predictors and correlates of adherence to combination antiretroviral therapy (ART) for chronic HIV infection: a meta-analysis. BMC Med 2014; 12: 142.

13. Fletcher D, Sarkar M. Psychological resilience: a review and critique of definitions, concepts, and theory. European Psychologist 2013; 18: 12-23.

14. Yu X, Lau JT, Mak WW, Cheng Y, Lv Y, Zhang J. A pilot theorybased intervention to improve resilience, psychosocial well-being, and quality of life among people living with HIV in rural China. J Sex Marital Ther 2014; 40: 1-16.

15. Fang X, Vincent W, Calabrese SK, et al. Resilience, stress, and life quality in older adults living with HIV/AIDS. Aging Mental Health 2015; 19: 1015-1021.

16. Mohammadkhani S, Haddadi Kuhsar AA, Soleimani H, Eatemadi A, Seyd Ali Naghei SA. A Prediction of resilience from cognitive emotion regulation in individuals with HIV infection. Health Psychology 2017; 6: 104-115.

17. Seligman MEP, Rashid TAC. Positive psychotherapy. American Psychologists 2006; 61: 774-788.

18. Ghasemi Khaneghah B. The effectiveness of positive psychotherapy on resilience and psychosocial adjustment of cancer patients. Fifth National Conference on Recent Innovations Recent National Innovations in Psychology, Applications and Empowerment with a Focus on Psychotherapy; 2019.

19. Hendriks T, Schotanus-Dijkstra M, Hassankhan A, et al. Resilience and well-being in the Caribbean: findings from a randomized controlled trial of a culturally adapted multi-component positive psychology intervention. Journal of Positive Psychology 2020; 15: 238-253.

20. Hayes SC. Acceptance and commitment therapy, relational frame theory, and the third wave of behavioral and cognitive therapies republished article. Behav Ther 2016; 47: 869-885.

21. Sri Suyanti T, Anna Keliat B, Catharina Daulima NH. Effect of logotherapy, acceptance, commitment therapy, family psychoeducation on self-stigma, and depression on housewives living with HIV/ AIDS. Enferm Clin 2018; 28 (Suppl 1): 98-101.

22. Faezipour M, Ghanbaripanah A, SeyedAlinaghi SA, Hajiabdolbaghi M, Voltareli F. Effectiveness of acceptance and commitment therapy on reducing depression among people living with HIV/ AIDS. J Int Transl Med 2018; 6: 125-129.

23. Smkhani Akbarinejhad H, Faroughi P. Comparison of the effectiveness of acceptance and commitment therapy and logotherapy on the psychological well-being and death anxiety of women with AIDS. Qom Univ Med Sci J 2021; 4: 48-60.

24. Ware JE, Sherbourne CD. The MOS 36-item short-form health survey (SF-36). I. Conceptual framework and item selection. Med Care 1992; 30: 473-483.

25. Karimpour J. The effectiveness of mindfulness-based stress reduction (MBSR) program on quality of life, perceived stress and psychological well-being of cardiovascular patients. Islamic Azad University ofScience and Research Campus (Hormozgan) Master Thesis (M.A.); 2014.

26. Connor KM, Davidson JR. Development of a new resilience scale: the conner-davidson resilience scale (CD-RISC). Depress Anxiety 2003; 18: 76-82.

27. Kurdmirza Nikozadeh E. Comparison of the effectiveness of an intervention program based on positive psychology and Adlerian group therapy in promoting resilience of drug addicts. Culture of Counseling 2011; 2: 1-27.

28. Asarzadegan M, Raeisi Z. The effectiveness of education based on positive psychotherapy on quality of life and happiness in patients with type 2 diabetes. Health Psychology 2019; 8: 98-116.

29. Mohammadpour Doghabadi N. Evaluation of the effectiveness of group therapy with the intervention of hope method on quality of life and hope of women living with HIV. Master Thesis in Clinical Psychology majoring in Family Therapy. University of Knowledge and Culture; 2016. 
Comparison of the effectiveness of positive thinking training and acceptance and commitment therapy on quality of life and resilience of people living with HIV

30. Arjun BY, Unnikrishnan B, Ramapuram JT, et al. Factors influencing quality of life among people living with HIV in coastal South India. J Int Assoc Provid AIDS Care 2017; 16: 247-253.

31. Hayes SC, Strosahl KD. A practical guide to acceptance and commitment therapy. New York: Springer Press; 2010.

32. Mohammadinejad M, Nikonejad F. The effectiveness of treatment based on acceptance and commitment (ACT) on psychological well-being and resilience of mothers with deaf girls in Isfahan. Knowledge and Research in Applied Psychology 2020; 21: 22-31.

33. Yildırım M, Arslan G. Exploring the associations between resilience, dispositional hope, preventive behaviors, subjective well-being, and psychological health among adults during early stage of COVID-19.CurrPsychol2020.DOI:https://doi.org/10.1007/s12144020-01177-2.

34. Heyes SC, Strosahl KD, Wilson KG. Acceptance and Commitment Therapy: an Experiential Approach to Behavior Change. New York: Guilford; 1999. 